\title{
Glypican-3 level assessed by the enzyme-linked immunosorbent assay is inferior to alpha-fetoprotein level for hepatocellular carcinoma diagnosis
}

\author{
Yejoo Jeon", Eun Sun Jang", Yun Suk Choi, Jin-Wook Kim, and Sook-Hyang Jeong \\ Department of Internal Medicine, Seoul National University College of Medicine, Seoul National University Bundang Hospital, \\ Seongnam, Korea
}

Background/Aims: Glypican-3 (GPC3) protein is highly expressed in hepatocellular carcinoma (HCC) tissue. It has been suggested as a diagnostic biomarker, but its inconsistent performance means that it requires further assessment. We therefore investigated the diagnostic value of the plasma GPC3 level compared to the alpha-fetoprotein (AFP) level as a diagnostic biomarker of HCC.

Methods: We enrolled 157 consecutive patients with newly diagnosed HCC and 156 patients with liver cirrhosis (LC) as the control group. GPC3 plasma levels were measured using two commercially available enzyme-linked immunosorbent assays (ELISAs, named as Assay 1 and 2), and AFP levels were measured using an enzyme-linked chemiluminescent immunoassay. The diagnostic accuracy was analyzed using the receiver operating characteristics (ROC) curve.

Results: Plasma GPC3 levels in HCC patients were very low $(0-3.09 \mathrm{ng} / \mathrm{mL})$ in Assay 1, while only 3 of the 157 patients (1.9\%) showed detectable GPC3 levels in Assay 2. The median GPC3 level was not significantly elevated in the HCC group $(0.80 \mathrm{ng} / \mathrm{mL})$ compared with the LC group $(0.60 \mathrm{ng} / \mathrm{mL})$. The area under the ROC curve (AUC) for GPC3 was 0.559 in Assay 1. In contrast, the median AFP level was significantly higher in HCC $(27.72 \mathrm{ng} / \mathrm{mL})$ than in LC $(4.74 \mathrm{ng} / \mathrm{mL})$, with an AUC of 0.729 .

Conclusions: The plasma level of GPC3 is a poor diagnostic marker for HCC, being far inferior to AFP. The development of a consistent detection system for the blood level of GPC3 is warranted. (Clin Mol Hepatol 2016;22:359-365)

Keywords: Alpha-fetoprotein; Biomarkers; Diagnosis; Glypican-3; Hepatocellular carcinoma; Sensitivity, Specificity

\section{INTRODUCTION}

Hepatocellular carcinoma (HCC) accounts for $80-90 \%$ of liver cancer, which is the $6^{\text {th }}$ most frequent cancer and the third leading cause of all cancer related deaths. ${ }^{1,2}$

While typical diagnostic methods for HCC include imaging methods and histological analysis, in the former it is difficult to detect and differentiate small nodules, whereas the latter is invasive and holds high-risk, especially in patients with cirrhotic backgrounds. Blood alpha-fetoprotein (AFP) levels have been used as a marker for HCC diagnosis and to supplement radiological findings. The Asian Pacific Association for the Study of the Liver guidelines

\author{
Abbreviations: \\ AFP, alpha-fetorprotien; BCLC, Barcelona Clinic Liver Cancer; ELICA, enzyme- \\ linked chemiluminescent immunoassay; ELISA, enzyme-linked immunosorbent \\ assay; GPC3, glypican-3; GPI, glycophosphatidylinositol; HBV, hepatitis B virus; \\ HCC, hepatocellular carcinoma; HCV, hepatitis C virus; LC, liver cirrhosis; ROC, \\ receiver operating characteristic
}

\section{Corresponding author: Sook-Hyang Jeong}

Department of Internal Medicine, Seoul National University College of Medicine, Seoul National University Bundang Hospital, 82 Gumi-ro 173beon-gil, Bundang-gu, Seongnam 13620, Korea

Tel: +82-31-787-7029, Fax: +82-31-787-4052

Email: jsh@snubh.org 
recommend AFP as a tumor marker for HCC with a cutoff value at $200 \mathrm{ng} / \mathrm{mL}$ in addition to radiological examinations. ${ }^{3}$ However, the current guidelines of the American Association for the Study of Liver Disease and the European Association for the Study of the Liver have excluded AFP based on its limited accuracy. ${ }^{4}$ AFP has moderate sensitivity for HCC, but lacks specificity as it is elevated in benign hepatic condition including cirrhosis and hepatitis. ${ }^{5}$ Therefore, additional biomarkers that are HCC-specific and -sensitive require investigation.

The heparin sulfate proteoglycan glypican-3 (GPC3) is a member of the glypican family and is bound to the membrane through a glycophosphatidylinositol (GPI) anchor. ${ }^{6}$ It is highly expressed in HCC cells and promotes HCC proliferation through the canonical Wnt pathway, and therapeutic methods that target GPC3 are currently being investigated. ${ }^{6-8}$ However, GPC3 elevation in the sera of HCC patients is less conclusive. Initial studies reported high sensitivity of GPC3 as a specific biomarker for HCC. ${ }^{5,9}$ Nonetheless, subsequent studies have led to inconsistent results, questioning plasma GPC3's value as a diagnostic biomarker. ${ }^{6}$ The aim of this study was to address this concern by assessing and comparing the diagnostic accuracy of GPC3 and AFP plasma level in a South Korean HCC population.

\section{PATIENTS AND METHODS}

\section{Patients}

The study design was a cross sectional, retrospective, case-control study including 157 HCC patients and a control group of 156 liver cirrhosis (LC) patients at the Seoul National University Bun- dang Hospital (Seongnam, Republic of Korea) from August 2006 through September 2013. This study was approved by the Seoul National University Bundang Hospital's Institutional Review Board (IRB, B-1307/210-006). Informed consent was confirmed by the IRB and received from all HCC patients. LC plasma samples were derived from repository samples, and thus informed consent was waived by the IRB.

HCC was diagnosed by histological and imaging findings outlined by American Association for the Study of Liver Disease guidelines and staged by the Barcelona Clinic Liver Cancer (BCLC) system. Patients with double primary cancer in non-liver organs or those who underwent intent-to-cure treatment (resection, liver transplantation, radiofrequency ablation, transarterial chemoembolization, or percutaneous ethanol injection) were excluded from this study. LC was diagnosed by histological examination or by one or more clinical findings of portal hypertension: 1) cirrhotic appearance of the liver with splenomegaly on imaging studies (ultrasonography, computed tomography or magnetic resonance image), 2) thrombocytopenia (platelet $<120,000 / \mathrm{mm}^{3}$ ), 3) presence of esophagogastric varices on endoscopy, 4) presence of ascites, and 5) presence of portosystemic encephalopathy. LC patients for whom the presence of HCC was not evaluated within six months before enrollment were excluded.

\section{Sample storage and measurement of AFP and GPC3}

Blood samples were collected from HCC patients before curative treatment and from $\mathrm{LC}$ patients at the time of clinic visit. Plasma aliquots were stored at $-70^{\circ} \mathrm{C}$ until time of measurement. Plasma AFP was measured using an automated enzyme-linked chemiluminescent immunoassay (ELICA). Plasma GPC3 levels

Table 1. Descriptions of Assay 1 and Assay 2 used to measure plasma GPC3 levels

\begin{tabular}{|c|c|c|}
\hline Category & Assay 1 & Assay 2 \\
\hline Manufacturer & USCN Life Science Inc. & R\&D Systems, Inc. \\
\hline Capture antibody & Monoclonal mouse & Monoclonal mouse \\
\hline Detection antibody & Polyclonal rabbit & Polyclonal sheep \\
\hline Plate & Pre-coated with capture antibody & Manual capture antibody coating \\
\hline Incubation temperature & $37^{\circ} \mathrm{C}$ & Room temperature \\
\hline Biotin binding protein & Avidin & Streptavidin \\
\hline Wash & $\begin{array}{l}\text { Aspirate but no wash between adding } \\
\text { sample and detecting antibody }\end{array}$ & $\begin{array}{l}\text { Aspirate and wash between adding } \\
\text { sample and detecting antibody }\end{array}$ \\
\hline Detection range & $0.156 \mathrm{ng} / \mathrm{mL}-10 \mathrm{ng} / \mathrm{mL}$ & $0.312 \mathrm{ng} / \mathrm{mL}-20 \mathrm{ng} / \mathrm{mL}$ \\
\hline Sample dilution factor & $1: 1$ & $1: 100$ \\
\hline
\end{tabular}


were assessed using two different commercially available enzymelinked immunosorbent assay (ELISA) kits named as Assay 1 and 2 (Assay 1: USCN Life Science Inc., Wuhan, China and Assay 2: R\&D Systems, Inc., Minneapolis, MN, USA), which were compared in Table 1. Tests were performed in accordance to manufacturer's instructions and in duplicates by two experienced researchers (YSC and YJ). In Assay 2, a sample dilution of 1:1 did not yield results within the range studied. Sample dilutions (1:1, 1:10, 1:50, 1:100, 1:500, and 1:1000) showed that 1:100 yielded consistent and peak GPC3 values. This dilution factor was therefore used for all samples.

\section{Statistical analysis}

Pearson's $\chi^{2}$ (categorical variables), Student's independent t-test (continuous parametric variables), and Mann-Whitney $U$ test (continuous nonparametric variables) were used to compare HCC and LC groups. Significance was defined as $P<0.05$. Receiver operating characteristic (ROC) curve and area under the curve (AUC) analyses were performed to compare diagnostic accuracies of

Table 2. Clinical characteristics of the study population

\begin{tabular}{|c|c|c|c|c|}
\hline & $\begin{array}{c}\text { Total } \\
(\mathrm{N}=313)\end{array}$ & $\begin{array}{c}\text { LC } \\
(\mathrm{N}=156)\end{array}$ & $\begin{array}{c}\text { HCC } \\
(\mathrm{N}=157)\end{array}$ & $P$-value \\
\hline Age, year* & $58.8(11.5)$ & $56.7(10.8)$ & $60.8(11.8)$ & 0.002 \\
\hline \multicolumn{5}{|l|}{ Gender $^{\dagger}$} \\
\hline Male & $217(69.3)$ & $90(57.7)$ & $127(80.9)$ & $<0.001$ \\
\hline Female & $96(30.7)$ & $66(42.3)$ & $30(19.1)$ & \\
\hline $\mathrm{BMl}, \mathrm{kg} / \mathrm{m}^{2 *}$ & $23.88(4.12)$ & $23.92(4.6)$ & $23.84(3.6)$ & 0.860 \\
\hline \multicolumn{5}{|l|}{ Etiology ${ }^{\dagger}$} \\
\hline Alcohol Consumption & $20(6.4)$ & $3(1.9)$ & $17(10.8)$ & \\
\hline HBV & $222(70.9)$ & $116(74.4)$ & $106(67.5)$ & \\
\hline $\mathrm{HCV}$ & $54(17.3)$ & $37(23.7)$ & $17(10.8)$ & \\
\hline Cryptogenic & $14(4.5)$ & $0(0.0)$ & $14(8.9)$ & \\
\hline Others & $3(0.9)$ & $0(0.0)$ & $3(1.9)$ & \\
\hline \multicolumn{5}{|l|}{ Child-Pugh class $^{\dagger}$} \\
\hline$A$ & $261(83.0)$ & $133(85.3)$ & $128(81.5)$ & 0.516 \\
\hline B & $45(14.8)$ & $19(12.2)$ & $26(16.6)$ & \\
\hline C & $7(2.3)$ & $4(2.5)$ & $3(1.9)$ & \\
\hline \multicolumn{5}{|l|}{ Underlying liver disease $^{\dagger}$} \\
\hline Chronic hepatitis & $10(3.2)$ & $0(0.0)$ & $10(6.4)$ & $<0.001$ \\
\hline Liver cirrhosis & $293(93.6)$ & $156(100.0)$ & $137(87.3)$ & \\
\hline \multicolumn{5}{|l|}{ Tumor characteristics ${ }^{\dagger}$} \\
\hline \multicolumn{5}{|l|}{ BCLC stage } \\
\hline 0 & - & - & $21(13.4)$ & \\
\hline A & - & - & $56(35.7)$ & \\
\hline B & - & - & $11(7.0)$ & \\
\hline C & - & - & $62(39.5)$ & \\
\hline $\mathrm{D}$ & - & - & $7(4.5)$ & \\
\hline Diffuse type & - & - & 18(11.5) & \\
\hline With major PVI & - & - & $32(20.4)$ & \\
\hline
\end{tabular}

LC, liver cirrhosis; HCC, hepatocellular carcinoma; BMI, body mass index; HBV, hepatitis B virus; HCV, hepatitis C virus; BCLC, barcelona clinic liver cancer; PVI, portal vein invasion.

*Mean (Standard Deviation).

${ }^{\dagger}$ Number (Percentage). 
GPC3 and AFP. The maximum sum of sensitivity and specificity on the ROC curve determined the GPC3 cut-off level. All statistical analyses were performed via SPSS Statistics 17.0 (SPSS Inc., Chicago, IL, USA).

\section{RESULTS}

\section{Characteristics of HCC patients and control group of cirrhosis patients}

The clinical characteristics of the study population (157 HCC and 156 LC) were summarized in Table 2. The HCC group had a higher proportion of males and was older than the LC control group. In both groups, hepatitis B virus (HBV) was the most common etiology $(67.5 \%$ in $\mathrm{HCC}$ and $74.4 \%$ in LC). Among the HCC patients, $6.4 \%$ and $87.3 \%$ had underlying liver diseases of chronic hepatitis and liver cirrhosis, respectively. There were no significant differences in Child-Pugh class between the two groups. BCLC staging was 0 in $13.4 \%$, A in $35.7 \%$, B in $7.0 \%, C$ in $39.5 \%$ and $\mathrm{D}$ in $4.5 \%$ of the HCC patients. Major portal vein invasion was observed in $20.4 \%$ of the HCC patients.

\section{Plasma levels of GPC3 and AFP in HCC and LC patients}

The median and mean levels of GPC3 and AFP were summarized in Table 3.

In Assay 1, the median GPC3 value for HCC patients was 0.80 $\mathrm{ng} / \mathrm{mL}$ (range, $0.00 \mathrm{ng} / \mathrm{mL}$ to $3.09 \mathrm{ng} / \mathrm{mL}$ ) for HCC patients, and for LC patients was $0.60 \mathrm{ng} / \mathrm{mL}$ (range, $0.07 \mathrm{ng} / \mathrm{mL}$ to $7.40 \mathrm{ng} /$ $\mathrm{mL})$. These differences were not significant $(P=0.255)$.

In Assay 2, all but 3 HCC samples were "Out of Range". None of the LC samples reached concentrations within the range of the assay. Because of the lack of HCC patients with detectable GPC3 levels, AUC analysis was not performed based on this data. Clinical characteristics and GPC3 concentrations based on Assay 1 and 2 of these samples were listed in Table 4.

Median plasma AFP level was $27.72 \mathrm{ng} / \mathrm{mL}$ (range, $0.72 \mathrm{ng} / \mathrm{mL}$ to $42,000.0 \mathrm{ng} / \mathrm{mL}$ ) in HCC patients and $4.74 \mathrm{ng} / \mathrm{mL}$ in LC patients (range, $1.08 \mathrm{ng} / \mathrm{mL}$ to $145.08 \mathrm{ng} / \mathrm{mL}$ ), which showed significantly elevated levels in HCC patients compared to LC patients $(P<0.001)$.

In addition, when comparing LC GPC3 and AFP median values to just that of early HCC patients ( $B C L C 0 \sim B, n=88$ ), again only AFP was significantly elevated in the latter (GPC3 $0.65 \mathrm{ng} / \mathrm{mL}$ $P=0.916, A F P=11.94 \mathrm{ng} / \mathrm{mL} P<0.001$; data not shown).

Table 3. Plasma GPC3 and AFP levels in HCC and LC patients

\begin{tabular}{|c|c|c|c|c|}
\hline & Total $(\mathrm{N}=313)$ & $\mathrm{LC}(\mathrm{N}=156)$ & $\mathrm{HCC}(\mathrm{N}=157)$ & $P$-value \\
\hline AFP level & & & & $<0.001$ \\
\hline Median & 7.44 & 4.74 & 27.72 & \\
\hline Range & $0.72-42000$ & $1.08-145.08$ & $0.72-42000.00$ & \\
\hline Mean & 1960.79 & 9.90 & 3899.26 & \\
\hline SD & 8026.26 & 17.72 & 11011.53 & \\
\hline GPC3 in Assay 1 & & & & 0.255 \\
\hline Median & 0.65 & 0.60 & 0.80 & \\
\hline Range & $0-7.40$ & $0.07-7.40$ & $0-3.09$ & \\
\hline Mean & 0.89 & 0.86 & 0.92 & \\
\hline SD & 0.78 & 0.86 & 0.69 & \\
\hline \multicolumn{5}{|l|}{ GPC3 in Assay 2 * } \\
\hline Median & 14.79 & All Results & 14.79 & \\
\hline Range & $10.59-83.16$ & Out of & $10.59-83.16$ & \\
\hline Mean & 36.18 & Range & 36.18 & \\
\hline SD & 40.74 & & 40.74 & \\
\hline
\end{tabular}

All values are in $\mathrm{ng} / \mathrm{mL}$.

GPC3, Glypican-3; AFP, Alpha-fetoprotein; HCC, Hepatocellular carcinoma; LC, Liver cirrhosis; SD, Standard deviation.

*Only three HCC samples had detectable GPC3 values. 
Yejoo Jeon, et al.

GPC3 by ELISA is inferior to AFP for HCC diagnosis

Table 4. Comparison of clinical characteristics for three patients with detectable plasma GPC3 levels in both ELISA assays

\begin{tabular}{|c|c|c|c|c|c|c|c|c|}
\hline \multirow{2}{*}{ Patient } & \multirow{2}{*}{ Age } & \multirow{2}{*}{ Etiology } & \multirow{2}{*}{ Cirrhosis } & \multirow{2}{*}{$\begin{array}{l}\mathrm{BCLC} \\
\text { stage }\end{array}$} & \multirow{2}{*}{ Tumor number } & \multirow{2}{*}{$\begin{array}{l}\text { Max tumor } \\
\text { size }(\mathrm{cm})\end{array}$} & \multicolumn{2}{|c|}{ GPC3 (ng/mL) } \\
\hline & & & & & & & Assay 1 & Assay 2 \\
\hline$A$ & 66 & HBV & Yes & A & 1 & 3.0 & 0.18 & 83.16 \\
\hline B & 62 & $\mathrm{HBV}$ & Yes & A & 2 & 1.7 & 1.11 & 14.79 \\
\hline C & 51 & HBV & Yes & C & 1 & 4.6 & 0.78 & 10.59 \\
\hline
\end{tabular}

ELISA, enzyme-linked immunosorbent assay; BCLC, barcelona clinic liver cancer; GPC3, glypican-3; HBV, hepatitis B virus.

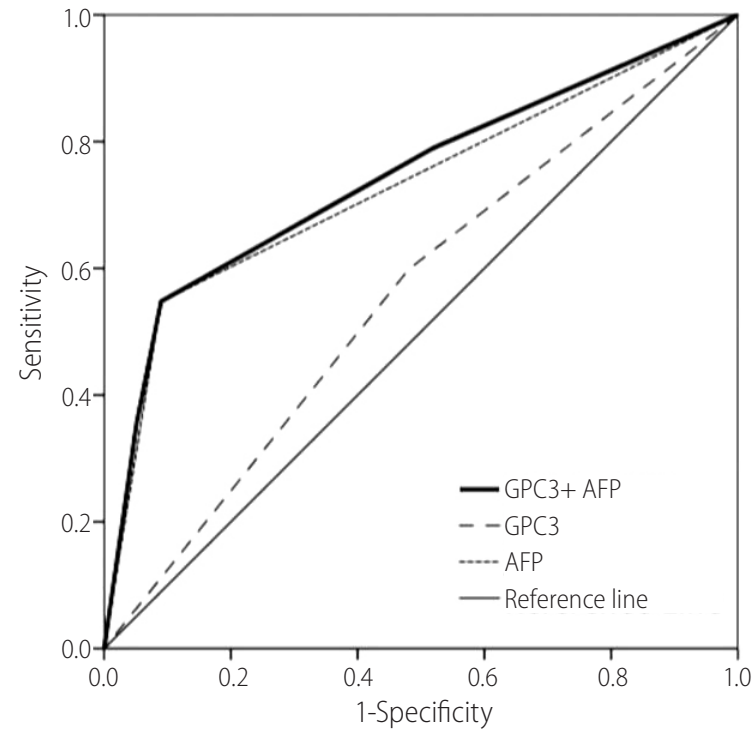

\begin{tabular}{|c|c|c|c|c|c|c|}
\hline Marker & $\begin{array}{c}\text { Cut-off } \\
\text { (ng/mL) }\end{array}$ & $\begin{array}{c}\text { Sn } \\
\text { (\%) }\end{array}$ & $\begin{array}{c}\text { Sp } \\
\mathbf{( \% )}\end{array}$ & $\begin{array}{c}\text { PPV } \\
\mathbf{( \% )}\end{array}$ & $\begin{array}{c}\text { NPV } \\
\mathbf{( \% )}\end{array}$ & $\begin{array}{c}\text { AUG } \\
\text { (Cl 95\%) }\end{array}$ \\
\hline GPC3 & 0.61 & 60 & 52 & 56 & 56 & $\begin{array}{c}0.559 \\
(0.495-0.623)\end{array}$ \\
\hline AFP & 20 & 55 & 91 & 86 & 67 & $\begin{array}{c}0.729 \\
(0.672-0.786)\end{array}$ \\
\hline $\begin{array}{c}\text { GPC3+ } \\
\text { AFP }\end{array}$ & $\begin{array}{c}0.61+ \\
20\end{array}$ & 55 & 91 & 86 & 67 & $\begin{array}{c}0.744 \\
(0.689-0.799)\end{array}$ \\
\hline
\end{tabular}

Figure 1. ROC curves of plasma GPC3 and AFP levels for HCC diagnosis. ROC curve of GPC3 (cut off level of $0.61 \mathrm{ng} / \mathrm{mL}$ ), AFP (cut off level of 20 $\mathrm{ng} / \mathrm{mL}$ ), combined GPC3 and AFP, and reference for hepatocellular carcinoma diagnosis displayed with data summary. ROC, receiver operating characteristic; GPC3, glypican-3; AFP, alpha-fetoprotein; Sn, sensitivity; Sp, specificity; PPV, positive predictive value; NPV, negative predictive value; AUC, area under the curve; $\mathrm{Cl}$, confidence interval.

\section{Diagnostic Accuracy of GPC3 and AFP}

Using the ROC curves (Fig. 1), AUCs were calculated to assess the diagnostic accuracy of plasma AFP and GPC3 for HCC. Based on maximum sum of sensitivity and specificity, a GPC3 cut-off of $0.61 \mathrm{ng} / \mathrm{mL}$ was determined. At this cut-off, GPC3 had a sensitivi- ty of $60 \%$ and a specificity of $52 \%$. At a cut-off of $20 \mathrm{ng} / \mathrm{mL}$, AFP had a sensitivity of a $55 \%$ and specificity $91 \%$. The AUC was 0.559 and 0.729 for GPC3 and AFP respectively, indicating AFP as a stronger diagnostic tool. Combining the two markers only provided a marginal change; GPC3 and AFP (at cut-offs of 0.61 $\mathrm{ng} / \mathrm{mL}$ and $20 \mathrm{ng} / \mathrm{mL}$ respectively) had an AUC of 0.744 , sensitivity of $55 \%$, and specificity of $91 \%$. Furthermore, when comparing the LC group to the early HCC subgroup, at the same cut-offs, AFP (AUC $=0.665)$ was a superior diagnostic biomarker compared to $G P C 3(A \cup C=0.527)$.

\section{DISCUSSION}

We set out to determine whether GPC3 could be useful as a diagnostic biomarker for HCC in comparison to the traditional AFP in an HBV endemic, South Korean background. While AFP levels were significantly elevated in HCC patients compared to LC patients, plasma GPC3 levels were either very low or undetectable. Our study reported comparable sensitivity, but much lower specificity and AUC values for GPC3 (52\% and 0.559) compared to other studies (84\% and 0.762). ${ }^{10}$ The ROC determined cut-off value for GPC3 of $0.61 \mathrm{ng} / \mathrm{mL}$ was lower than most reported values, though it has been reported to range from $3.9 \mathrm{pg} / \mathrm{mL}$ to $300 \mathrm{ng} /$ $\mathrm{mL} .^{10}$ Meanwhile, AFP sensitivity, specificity, and AUC were comparable to reported results. ${ }^{10}$ Overall, the plasma level of GPC3 was a poor diagnostic biomarker for HCC compared to AFP.

Though we used 2 commercially available GPC3 assays, GPC3 values detected by the two assays showed discrepancies. Assay 1 resulted in lower GPC3 values in HCC patients than those reported by previous studies, although some studies have reported similarly low values. ${ }^{11-14}$ In Assay 2, only 1.9\% of the HCC patients had detectable values in this study. The technical differences between the two assays included sample dilution factor and washing method. These differences may have contributed to discrepancies between the two assays.

Since first reported to be present in the plasma of $53 \%$ HCC 
Table 5. Summary of reported studies measuring blood GPC3 levels in HCC patients using ELISA

\begin{tabular}{|c|c|c|c|c|c|c|}
\hline Author (year) & Country & HCC cases & GPC3 mean & GPC3 median & GPC3 range & ELISA kit \\
\hline Beale et al. $(2008)^{13}$ & UK & 50 & $161.41 \mathrm{ng} / \mathrm{mL}$ & $56.57 \mathrm{ng} / \mathrm{mL}$ & & $\begin{array}{l}\text { BioMosaics limited } \\
\text { (Burlington, VT, USA) }\end{array}$ \\
\hline Yasuda et al. (2010) & Japan & 200 & & $924.8 \mathrm{pg} / \mathrm{mL}$ & & \\
\hline Lee et al. $(2014)^{15}$ & South Korea & 120 & & $75.8 \mathrm{ng} / \mathrm{mL}$ & $21.7-482.5 \mathrm{ng} / \mathrm{mL}$ & Cusabio (Wuhan, China) \\
\hline Wang et al $(2013)^{14}$ & China & 84 & & $4.55 \mathrm{ng} / \mathrm{mL}$ & & \\
\hline Badr et al. $(2014)^{16}$ & Egypt & 30 & $551.47 \mu \mathrm{g} / \mathrm{mL}$ & & & $\begin{array}{l}\text { USCN Life Science Inc. } \\
\text { (Wuhan, China) }\end{array}$ \\
\hline El Gawad et al. (2014) ${ }^{17}$ & Egypt & 40 & & $7.7 \mathrm{ng} / \mathrm{mL}$ & & \\
\hline El-Shenawy et al. (2012) ${ }^{18}$ & Egypt & 85 & $1,646.3 \mathrm{ng} / \mathrm{mL}$ & & & \\
\hline Ozkan et al. $(2011)^{12}$ & Turkey & 75 & & $3.9 \mathrm{pg} / \mathrm{mL}$ & & $\begin{array}{c}\text { ElAab Science Co. } \\
\text { (Wuhan China) }\end{array}$ \\
\hline Capurro et al. $(2003)^{5}$ & Canada & 34 & & & $0-2924 \mathrm{ng} / \mathrm{mL}$ & Non-Commercial \\
\hline Chen et al. $(2013)^{19}$ & China & 155 & $99.94 \mathrm{ng} / \mathrm{mL}$ & $15.11 \mathrm{ng} / \mathrm{mL}$ & $0-2400.00 \mathrm{ng} / \mathrm{mL}$ & \\
\hline Hippo et al. $(2004)^{9}$ & Japan & 69 & $4.84 \mathrm{ng} / \mathrm{mL}$ & & & \\
\hline Tangkijvanich et al. (2010) ${ }^{* 20}$ & Thailand & 100 & & $46.3 \mathrm{ng} / \mathrm{mL}$ & $0-7826.6 \mathrm{ng} / \mathrm{mL}$ & \\
\hline
\end{tabular}

* Reported to use same procedure as (5).

GPC3, glypican-3; HCC, hepatocellular carcinoma; ELISA, enzyme-linked immunosorbent assay.

patients but undetectable in healthy liver controls, GPC3 has been studied as a biomarker for HCC to replace or complement AFP. ${ }^{5}$ However, subsequent studies have yielded inconsistent results as summarized in Table 5, showing inter- and intra-ELISA variances. Differences in capture and detection antibodies could explain inter-method differences. ${ }^{5,9,11-20}$ While Capurro et al. developed antibodies targeting the $\mathrm{COOH}$-terminus for their ELISA, Hippo et al. used antibodies targeting the NH2-terminus. ${ }^{5,9}$ Though Capurro et al. and Hippo et al. reported similarly elevated rates of GPC3 in HCC patients ( $53 \%$ and $51 \%$, respectively), their scales were completely different $(0-2924 \mathrm{ng} /$ $\mathrm{mL}$ vs 0 - $60 \mathrm{ng} / \mathrm{mL})^{5,9}$

The nature of plasma GPC3 may impact ELISA utility. Plasma GPC3 can be produced when an extracellular lipase (Notum) cleaves the GPI anchor of membrane bound GPC3 or when secreted, possibly by endogenous Notum or GPI-phospholipase D, by the cell. ${ }^{21}$ Various species of GPC3 may also be found, as Hippo et al. was able to detect a 50-kDa fragment produced by a cleavage site in the $\mathrm{COOH}$-terminal in addition to the commonly detected glycanated GPC3. ${ }^{22}$ Furthermore, plasma GPC3 competitively binds with several growth factors, which could interfere with antibody binding. ${ }^{23}$ Given these possibilities, it is clear that a uniform understanding of plasma GPC3 has not been reached. There may be ways to circumvent these proposed obstacles. Comparison of cell lysate and supernatant could help differentiate membrane bound and secreted GPC3; an antibody that targets the $\mathrm{NH} 2$ terminal may detect both the $50 \mathrm{kDa}$ and glycanated forms of GPC3; and a dilution of the plasma could help prevent interference of antibody binding. ${ }^{22}$ Nonetheless, for plasma GPC3 to be a universal biomarker, the biochemistry behind plasma GPC3 concerning its origin as well as structure(s) must be elucidated.

Finally, heterogeneity in HCC composition, ethnicity, etiology, and clinical manifestation may lead to variability. ${ }^{8,24}$ Moreover, meta-studies point out methodological issues such as differences in inclusion and exclusion criteria or use of reference standard tests. ${ }^{6,10}$

The limitations of this study were that it was a single center, cross-sectional design without external validation samples, no assessment of concurrent GPC3 tissue expression, and usage of plasma samples. It also included only 2 commercially available ELISA.

In conclusion, plasma GPC3 level measured by currently available 2 ELISA kits clearly failed to be a useful diagnostic biomarker for HCC compared to AFP. Persistent inconsistency in GPC3 values questions its utility. Future studies regarding the development of more reliable detection systems perhaps including blood GPC3 levels are warranted. 


\section{Funding support}

This study was supported by an intramural grant (No.02-2014024) from the Seoul National University Bundang Hospital. We are grateful to Hyein Mann of Seoul National University Bundang Hospital for her devotion to sample collection and storage. We are also grateful to Professor Emeritus J. Patrick Barron Ph.D. of Tokyo Medical University for his pro bono editing of this manuscript.

\section{Conflicts of Interest}

The authors have no conflicts to disclose.

\section{REFERENCES}

1. Feng M, Ho M. Glypican-3 antibodies: a new therapeutic target for liver cancer. FEBS Lett 2014;588:377-382.

2. Zhu AX, Gold PJ, El-Khoueiry AB, Abrams TA, Morikawa H, Ohishi $N$, et al. First-in-man phase I study of GC33, a novel recombinant humanized antibody against glypican-3, in patients with advanced hepatocellular carcinoma. Clin Cancer Res 2013;19:920-928.

3. Omata M, Lesmana LA, Tateishi R, Chen PJ, Lin SM, Yoshida H, et al. Asian Pacific Association for the Study of the Liver consensus recommendations on hepatocellular carcinoma. Hepatol Int 2010;4:439-474.

4. Song do S, Bae SH. Changes of guidelines diagnosing hepatocellular carcinoma during the last ten-year period. Clin Mol Hepatol 2012;18:258-267.

5. Capurro M, Wanless IR, Sherman M, Deboer G, Shi W, Miyoshi E, et al. Glypican-3: a novel serum and histochemical marker for hepatocellular carcinoma. Gastroenterology 2003;125:89-97.

6. Liu XF, Hu ZD, Liu XC, Cao Y, Ding CM, Hu CJ. Diagnostic accuracy of serum glypican-3 for hepatocellular carcinoma: a systematic review and meta-analysis. Clin Biochem 2014;47:196-200.

7. Filmus J, Capurro M, Rast J. Glypicans. Genome Biol 2008;9:224.

8. Filmus J, Capurro M. Glypican-3: a marker and a therapeutic target in hepatocellular carcinoma. FEBS J 2013;280:2471-2476.

9. Hippo Y, Watanabe K, Watanabe A, Midorikawa Y, Yamamoto S, Ihara $S$, et al. Identification of soluble $\mathrm{NH2}$-terminal fragment of glypican-3 as a serological marker for early-stage hepatocellular carcinoma. Cancer Res 2004;64:2418-2423.

10. Jia X, Liu J, Gao Y, Huang Y, Du Z. Diagnosis accuracy of serum glypican-3 in patients with hepatocellular carcinoma: a systematic review with meta-analysis. Arch Med Res 2014;45:580-588.

11. Yasuda E, Kumada T, Toyoda H, Kaneoka Y, Maeda A, Okuda S, et al. Evaluation for clinical utility of GPC3, measured by a commercially available ELISA kit with Glypican-3 (GPC3) antibody, as a serological and histological marker for hepatocellular carcinoma. Hepatol Res 2010;40:477-485.

12. Ozkan H, Erdal H, Kocak E, Tutkak H, Karaeren Z, Yakut M, et al. Diagnostic and prognostic role of serum glypican 3 in patients with hepatocellular carcinoma. J Clin Lab Anal 2011;25:350-353.

13. Beale G, Chattopadhyay D, Gray J, Stewart S, Hudson M, Day C, et al. AFP, PIVKAll, GP3, SCCA-1 and follisatin as surveillance biomarkers for hepatocellular cancer in non-alcoholic and alcoholic fatty liver disease. BMC Cancer 2008;8:200.

14. Wang $Y$, Yang $H, X u$ H, Lu X, Sang $X$, Zhong $S$, et al. Golgi protein 73, not Glypican-3, may be a tumor marker complementary to alpha-Fetoprotein for hepatocellular carcinoma diagnosis. J Gastroenterol Hepatol 2014;29:597-602.

15. Lee HJ, Yeon JE, Suh SJ, Lee SJ, Yoon EL, Kang K, et al. Clinical utility of plasma glypican-3 and osteopontin as biomarkers of hepatocellular carcinoma. Gut Liver 2014;8:177-185.

16. Badr EAE, Korah TE, Ghani AA, El-Sayed S, Badr S. Role of serum glypican-3 in the diagnosis and differentiation of small hepatocellular carcinoma from hepatitis-C virus cirrhosis. Alexandria Med J 2014;50:221-226.

17. Abd El Gawad IA, Mossallam GI, Radwan NH, Elzawahry HM, Elhifnawy NM. Comparing Prothrombin induced by vitamin $\mathrm{K}$ absence-II (PIVKA-II) with the oncofetal proteins Glypican-3, Alpha feto protein and Carcinoembryonic antigen in diagnosing hepatocellular carcinoma among Egyptian patients. J Egypt Natl Canc Inst 2014;26:79-85

18. El-Shenawy S, El Sabawi M, Sheble N, Abd El-Raof M, Allam M, Fath Allah S. Diagnostic role of serum Glypican-3 as a tumor marker for hepatocellular carcinoma. Nat Sci 2012;10:32-38

19. Chen M, Li G, Yan J, Lu X, Cui J, Ni Z, et al. Reevaluation of glypican-3 as a serological marker for hepatocellular carcinoma. Clin Chim Acta 2013;423:105-111.

20. Tangkijvanich $P$, Chanmee T, Komtong S, Mahachai V, Wisedopas $N$, Pothacharoen $P$, et al. Diagnostic role of serum glypican-3 in differentiating hepatocellular carcinoma from non-malignant chronic liver disease and other liver cancers. J Gastroenterol Hepatol 2010;25:129-137.

21. Traister A, Shi W, Filmus J. Mammalian Notum induces the release of glypicans and other GPI-anchored proteins from the cell surface. Biochem J 2008:410:503-511.

22. Capurro M, Filmus J. Glypican-3 as a serum marker for hepatocelIular carcinoma. Cancer Res 2005;65:372.

23. Zittermann SI, Capurro MI, Shi W, Filmus J. Soluble glypican 3 inhibits the growth of hepatocellular carcinoma in vitro and in vivo. Int J Cancer 2010;126:1291-1301.

24. Bedossa P, Paradis V. Hepatocellular Carcinoma. Practical Hepatic Pathology: A Diagnostic Approach. In: Saxena R, ed. Hepatocellular Carcinoma, Vol I. Philadelphia: Elsevier Inc., 2011:489-501. 